\title{
Synthesis and Microstructure Characterization of Novel Sr-HA Prepared by Co-precipitation with Enhanced Bioactivity
}

\author{
M.I. El-Gohary, S.M. El-Dyn", B.M. Abd El-moniem**, \\ E. Al-Ashkar ${ }^{* *}$, S. saleh ${ }^{*}$, E. Tolba ${ }^{* *}$ and I. Soliman \\ Physics Department, Biophysics Branch, Faculty of Science, \\ Al-Azhar University (boys), "Physics Department, Biophysics \\ Branch, Faculty of Science, Al-Azhar University (girls), Nasr \\ City and ${ }^{* *}$ Biomaterials Department, National Research \\ Center, Cairo, Egypt.
}

\begin{abstract}
THERE IS accumulating evidence that strontium-containing biomaterials have positive effects on bone tissue repair. In this study, a series of Sr-substituted hydroxyapatites $\left(\mathrm{Sr}_{\mathrm{x}} \mathrm{Ca}_{1-\mathrm{x}}\right)_{5}\left(\mathrm{PO}_{4}\right)_{3} \mathrm{OH}$, where $\mathrm{x}=0.00,0.5,1.00$ and 2.00 were made by the co-precipitation method. The microstructure analyses of obtained apatite after incorporation of $\mathrm{Sr}$ were evaluated by using X-ray Diffraction (XRD), Fourier transform infrared spectroscopy (FT-IR), Scanning electron microscope (SEM) and Thermo gravimetric analysis (TGA) Moreover, bioactivity of samples was examined by soaking samples in the simulated body fluid solution (SBF). Strontium is quantitatively incorporated into hydroxyapatite where its substitution for calcium provokes a linear increase in the lattice constants and a linear shift of the infrared absorption bands of the hydroxyl and phosphate groups, coherent with the greater ionic radius of strontium .Also incorporation of $\mathrm{Sr}$ into hydroxyapatite provokes its thermal stability and bioactivity. The obtained results indicate that Sr-HA have high potential to be used as a resorbable scaffold material release therapeutic agent to enhance osteogenesis and bone regeneration.
\end{abstract}

Keywords: Hydroxyapatite, Sr-substituted hydroxyapatite, Crysta size, Bioactivity, Simulated body fluid.

Worldwidly, the rise in life expectancy has led to an increased demand for new restoring and augmentation materials, with application in treatment therapies for bone defects ${ }^{(1)}$. These new compositions must tackle the bone regeneration therapies in a more efficient and durable way. The current scenario regarding treatments of bone disorders is that over 2.2 million persons are surgically treated each year as consequence of trauma or tumor extirpation ${ }^{(2)}$. The gold standard for grafting and repair is the reconstruction with autografts. However, the limitation of tissue amount and the morbidity at the extraction site have resulted in a high interest for synthetic materials ${ }^{(3)}$. An ideal bone graft should be reabsorbable and guide the patient's bone tissue towards a regenerative process ${ }^{(4)}$. Moreover, the graft should exhibit chemical, physical and biological properties appropriate to 
the implantation site, especially when implanted as a solid piece or as porous scaffolds. Despite the research efforts in the field of ceramics, metals and polymers, the availability of this ideal material is still far away for clinical practice and a challenge ${ }^{(5)}$.

Bone is a dynamic and highly vascularized tissue that continues to remodel throughout the lifetime of an individual. It plays an integral role in locomotion, ensures the skeleton has adequate load-bearing capacity, and acts as a protective casing for the delicate internal organs of the body. In addition to these structural functions, bone is intimately involved in homeostasis through its storage of $\mathrm{Ca}$ and $\mathrm{P}$ ions and by regulating the concentration of key electrolytes in the blood ${ }^{(6)}$. Beside $\mathrm{Ca}$ and $\mathrm{P}$, bone apatite is substituted by many different trace elements occurring in smaller concentration. Since many trace elements, such as $\mathrm{Sr}, \mathrm{Mg}$, $\mathrm{Zn}$ or Si present in the human body, are known for their anabolic effects in bone metabolism, new approaches for enhancing bioactivity of scaffold materials are being investigated by introducing therapeutic ions into the scaffold material ${ }^{(7)}$.

Strontium is known to accelerate bone healing processes and have positive effects on bone tissue repair. In vitro and in vivo studies have indicated that strontium increases bone formation and reduces osteoporosis, leading to a gain in bone mass and improved bone mechanical properties in normal animals and humans. Thus, research efforts are devoted to incorporate these $\mathrm{Sr}$ ions in synthetic apatites resulting in the changed dissolution behaviour of these materials and their modified (usually improved) biological performance ${ }^{(8)}$.

In this study, Sr substituted hydroxyapatite ceramics were prepared by the coprecipitation method. The effect of incorporation of $\mathrm{Sr}$ ions on both physical and biological properties of hydroxyapatite was reported. The prepared samples were characterized using different techniques. Moreover, the bioactivity and biodegradability tests in a simulated body fluid (SBF) were evaluated.

\section{Materials and Methods}

\section{Preparation of $\mathrm{Sr}-\mathrm{HA}$}

Non-substituted and Sr-substituted hydroxyapatites are prepared by using the aqueous precipitation method. Pure hydroxyapatite (HA) was prepared by the aqueous precipitation method from Calcium nitrate tetra hydrate and ammonium dihydrogen phosphate as the starting material. Calculated amounts of $\left(\mathrm{Ca}\left(\mathrm{NO}_{3}\right)_{2}\right.$. $\left.4 \mathrm{H}_{2} \mathrm{O}\right)$ and $\left(\left(\mathrm{NH}_{4}\right) \mathrm{H}_{2} \mathrm{PO}_{4}\right)$ are dissolved in $1000 \mathrm{ml}$ of distilled water by taking into consideration that $\mathrm{Ca} / \mathrm{P}$ molar ratio is adjusted to about 1.67 and $\mathrm{pH}$ for each aqueous solution is kept at $10-11$ by the addition of ammonia solution when it is required. All the dissolution is performed at room temperature. After dissolution, the temperature of vigorously stirred $\left(\mathrm{Ca}\left(\mathrm{NO}_{3}\right)_{2} .4 \mathrm{H}_{2} \mathrm{O}\right)$ solution is raised until it reached $60{ }^{\circ} \mathrm{C}$, after that, the vigorously stirred $\left(\left(\mathrm{NH}_{4}\right) \mathrm{H}_{2} \mathrm{PO}_{4}\right)$ solution is added drop wise to the $\left(\mathrm{Ca}\left(\mathrm{NO}_{3}\right)_{2} .4 \mathrm{H}_{2} \mathrm{O}\right)$ solution at a $\mathrm{pH}$ kept at $10-11$. When dropping is completed, the temperature of solution is raised to about $100{ }^{\circ} \mathrm{C}$. After it reached $100^{\circ} \mathrm{C}$, the mother solution is kept for about 2 hours on the

Egypt. J. Biophys. Biomed. Engng. Vol. 13 (2012) 
stirrer. After that, the solution is aged overnight on which the precipitation of the solution is formed. On the next day the precipitated solution was filtered and washed several times with distilled water. Then it was dried at about $110^{\circ} \mathrm{C}$ and sintered at about $600{ }^{\circ} \mathrm{C}$. The sintered powders are sieved at $150 \mu \mathrm{m}{ }^{(9)}$. Strontium substituted hydroxyapatite was prepared by an analogous method, but with a reduction of the amount of $\mathrm{Ca}^{+2}$ and an addition of a calculated amount of $\mathrm{Sr}^{+2}$ in the form of strontium nitrate $\left(\left(\mathrm{Sr}\left(\mathrm{NO}_{3}\right)_{2}\right.\right.$ Sigma). Four different compositions were prepared which are named HA (pure), $\mathbf{S}_{\mathbf{1}}(0.5 \mathrm{wt} \%$ of $\mathrm{Sr}), \mathbf{S}_{\mathbf{2}}$ (1 wt $\%$ of $\mathrm{Sr}$ ) and $\mathbf{S}_{\mathbf{3}}(2 \mathrm{wt} \%$ of $\mathrm{Sr})$.

\section{Characterization techniques}

$X$-ray diffraction (XRD)

Phase analysis of the prepared samples are studied using X-ray diffractrometer (XRD, Bruker D8 Advanced $\mathrm{Cu}$ target with secondary monochromator) operated at $40 \mathrm{kV}$ and tube current of $40 \mathrm{~mA}$. Diffraction patterns were compared to ICDD database PDF patterns of $\mathrm{Ca}_{10}\left(\mathrm{PO}_{4}\right)_{6}(\mathrm{OH})_{2}$ (HA), (JCPDS No.024-0033).

The crystal size of the precipitates was estimated from the XRD pattern using the Scherrer equation.

$$
D_{h k l}=\frac{K \lambda}{\beta \backslash \operatorname{Cos} \theta_{h k l}} \rightarrow--------1
$$

where $\mathrm{K}$ is a constant varying with the method of measuring the broadening and is chosen to be $0.9, \lambda$ is the wavelength $(\mathrm{nm})$ of $\mathrm{Cu} \mathrm{K} \mathrm{K}_{\alpha}$ radiation $(\lambda=0.15418 \mathrm{~nm}), \beta$ corresponds to full width at half maximum (FWHM) for the peak hkl (rad) and $\theta$ is the diffraction angle (in degrees) ${ }^{(\mathbf{1 0})}$.

The degree of crystallinity corresponding to the fraction of crystalline phase present in the examined volume can be estimated by X-ray diffraction data according to the following:

$$
X_{c}=1-\frac{V_{112 / 300}}{I_{300}} \rightarrow----------2
$$

where $X_{c}$ is the crystallinity degree, $I_{300}$ is the intensity of (300) reflection and $\mathrm{V}_{1121300}$ is the intensity of the hollow between (112) and (300) reflection ${ }^{(\mathbf{1 1}, 12)}$.

Fourier transform infrared spectroscopy (FT-IR)

Functional groups present on the prepared samples can be determined using the (FT-IR) technique. The (FT-IR) spectra are obtained in the region of 4000$400 \mathrm{~cm}^{-1}$ (wave number) using $\mathrm{KBr}$ pellet transmission technique with a resolution of $4 \mathrm{~cm}^{-1}$ where $0.002 \mathrm{~g}$ of powder samples were mixed with $0.198 \mathrm{~g}$ of $\mathrm{KBr}$ and then pressed into pellets. 
Thermal gravimetric analysis (TGA)

The weight changes of the prepared (uncalcined) powders were studied as a function of temperature by the thermal gravimetric analysis (TGA), Shimadzu TGA-50 Hz instrument .The test was performed at a heating rate of $10^{\circ} \mathrm{C} / \mathrm{min}$ under nitrogen atmosphere from RT up to $1000{ }^{\circ} \mathrm{C}$.

\section{Apatite formation ability}

The prepared powders are processed in the form of discs ( $\mathrm{HA}$ and $\mathrm{S}_{3}$ ) and then immersed in SBF solution that was prepared according to Kokubo and Takadama ${ }^{(13)}$. The samples are soaked for different periods; $1,2,6$ and 12 days, at $37^{\circ} \mathrm{C}$. The solutions are analyzed using the Inductively coupled plasma (ICP) that measure the change in $\mathrm{Ca}^{+2}, \mathrm{PO}_{4}^{-{ }^{3}}$ and $\mathrm{Sr}^{+2}$ ions concentration during soaking the samples in SBF (ICP, Model Ultima 2-Jobin Yvon) which operates between 1 and 5 kilowatts. Moreover, the $\mathrm{pH}$ of the $\mathrm{SBF}$ is measured using a $\mathrm{pH}$ meter (Fisher Scientific, Pittsburgh PA).

\section{Scanning electron microscope (SEM)}

The surface of prepared samples before and after soaking in SBF are investigated by scanning electron microscope (SEM, Jeol JxA 840). The samples were sputtered with gold by a sputter coater as an adhesive electric conductor.

\section{Results and Discussion}

\section{Phase identication by using XRD}

The XRD analysis of the HA and Sr-HA powder (Fig. 1), revealed that, they have a hexagonal shape showing the characteristic peaks of hydroxyapatite structure without secondary phase formation to detect due to the presence of $\mathrm{Sr}$ which demonstrates the complete substitution of $\mathrm{Sr}$ in the hydroxyapatite network.

The average crystallite size of the samples is calculated using the Scherrer formula (No.1.), as shown in Table1. At low Sr content (0.5 wt \%, 1 wt \%), crystal size of Sr-HA decreased as compared with that of HA. This may be due to at low strontium contents, Sr prefer to present only in a limited number of unit cells, and it is present in only afraction of $\mathrm{M}(1)$ site as this site allows the accommodation of a larger cation because of the longer bonds $\mathrm{M}(1)-\mathrm{O}$ mean distances. However, when the number of heavier ions increases $(2 \mathrm{wt} \% \mathrm{Sr}$ content), the repulsion between atoms in the $\mathrm{M}(1)$ position increases that causes Sr to prefer to occupy $M(2)$ sites as the strontium replacement of the calcium at $\mathrm{M}(2)$ sites allows a better accommodation of the heavier strontium atoms because in this position metal atoms form "staggered" equilateral triangles centered on the unit cell of apatite channel ${ }^{(14)}$. 




Fig.1. XRD of control (HA) and Sr-HA sintered at about $600{ }^{\circ} \mathrm{C}$.

TABLE 1. Crystal size, crystallinity and lattice parameters of Sr-HA reflected by XRD patterns

\begin{tabular}{|c|c|c|c|c|c|}
\hline \multirow{2}{*}{ Sample } & \multirow{2}{*}{$\begin{array}{c}\text { Sr content } \\
(\boldsymbol{\%})\end{array}$} & \multirow{2}{*}{$\begin{array}{c}\text { Crystallinity } \mathbf{x}_{\mathbf{c}} \\
(\boldsymbol{\%})\end{array}$} & \multicolumn{2}{|c|}{$\begin{array}{c}\text { Average Crystal } \\
\text { dimension d }(\mathbf{n m})\end{array}$} & \multicolumn{2}{|c|}{$\begin{array}{c}\text { Lattice } \\
\text { parameters }\end{array}$} \\
\cline { 5 - 7 } & & & & $\mathbf{a}$ & $\mathbf{c}$ \\
\hline control & 0 & 52 & 29.12 & 9.11 & 6.9014 \\
\hline$S_{1}$ & 0.5 & 47.58 & 25.30 & 9.12 & 6.9016 \\
\hline$S_{2}$ & 1 & 52.6 & 25.12 & 9.17 & 6.9022 \\
\hline$S_{3}$ & 2 & 53 & 29.59 & 9.18 & 6.9034 \\
\hline
\end{tabular}

The degree of crystallinity (calculated by No. 2) increases from $52 \%$ for control to $52.6-53 \%$ for $S_{2}$ and $S_{3}$, respectively but decreased to 47.58 for $S_{1}$ which matched with the observed broadening in the XRD peaks at $0.5 \% \mathrm{Sr}$ content. The broadening of the X-ray line width indicated that the incorporation of $\mathrm{Sr}$ at this content destroyed the symmetry. This may be due to a greater difficulty for HA to host the larger strontium ion than for SrHA to host the smaller calcium ion $\left(\mathrm{Ca}^{+2}\right.$ ionic radius $=0.100 \mathrm{~nm} ; \mathrm{Sr}^{+2}$ ionic radius $\left.=0.118 \mathrm{~nm}\right)^{(14)}$.

The effect of ion substitution on the crystal structure of hydroxyapatite is determined by detecting a variation in the lattice parameters (calculated by No. 3). The ionic radius of $\mathrm{Sr}$ is larger than that of $\mathrm{Ca}$ which is in agreement with the observed increase in lattice parameters for $\mathrm{Sr}-\mathrm{HA}$ as shown in Table 1. The change of lattice parameters of Sr-HA clearly demonstrated that $\mathrm{Sr}$ ion was structurally incorporated, in other words, they didn't just cover the surface of crystal $^{(15)}$. 
FT-IR spectroscopic studies

Figure 2 shows the FTIR spectra of pure hydroxyapatite and Sr-HA samples. All samples exhibit the characteristic pattern of partially carbonated hydrated hydroxyapatite, as extensively discussed elsewhere. The absorption bands at 1040,570 and $466 \mathrm{~cm}^{-1}$, detected in the spectrum, are attributed to the phosphate $\left(\mathrm{PO}_{4}^{-3}\right)$ characteristic absorption, were presented in all spectra for the synthetic apatites ${ }^{(16)}$. The $\mathrm{OH}^{-}$stretching mode is observed at $3573 \mathrm{~cm}^{-1}$, this band in the spectrum of $S_{1}$ has a lower intensity than those in $S_{2}$ and $S_{3}$ while $\mathrm{OH}^{-}$vibration mode is disappeared in all prepared samples ${ }^{(17)}$. The FTIR analysis shows the presence of B-type carbonation ( $\mathrm{v}_{3}$ carbonate vibrational mode) in the range $1417-1457 \mathrm{~cm}^{-1}$. Although there is no carbonate source in the solution such presence of carbonation on the prepared samples may be due to the carbon dioxide in the reaction vessel, since the synthesis process was performed under normal atmosphere ${ }^{(15)}$. It has been reported previously that co-substitution of $\mathrm{Sr}$ and carbonate in a calcium phosphate lattice could enhance the biocompatibility properties and dissolution rate of hydroxyapatite ${ }^{(18)}$. The band at about $875 \mathrm{~cm}^{-1}$ may be attributed to $\mathrm{HPO}_{4}{ }^{-2}$. The band due to adsorbed water was noticed at $1632 \mathrm{~cm}^{-1}$ while the band that observed at $3479 \mathrm{~cm}^{-1}$.This observed band of absorbed water may be referred to its entrance into the lattice of HA.



Fig .2. Infrared spectra of the Sr-HA prepared samples sintered at about $600{ }^{\circ} \mathrm{C}$.

Figure 2 shows how the bands due to the symmetric stretching $\left(v_{3}\right)$ and bending $\left(v_{4}\right)$ modes of phosphate groups shifts to lower wave number .The predominant factor causing shifts in the internal phosphate frequencies to lower energies is decreased anion-anion repulsion concomitant with an increased anion-anion separation on

Egypt. J. Biophys. Biomed. Engng. Vol. 13 (2012) 
increasing cation radius. Such changes may be attributed to the substitution $\mathrm{of}^{+2}$ for $\mathrm{Ca}^{+2}$ into the lattice of apatite, the greater ionic radius $\mathrm{of}^{+2}$ consequently decreases the bonding strength of $\mathrm{P}-\mathrm{O}$, the vibrations further confirm that $\mathrm{Sr}^{+2}$ can substitute $\mathrm{Ca}^{+2}$ and enter the lattice of apatite ${ }^{(19)}$. Similar observations were also made by other authors in the literature ${ }^{(17,20)}$. Also the intensity of $v_{2}$ phosphate band and of $\mathrm{OH}^{-1}$ stretching mode is increased with increasing $\mathrm{Sr}$ content but decreased on the spectrum of $\mathrm{S}_{1}$. This may be due to the increase on the degree of crystallinity with increasing $\mathrm{Sr}$ content for high $\mathrm{Sr}$ ratio $(1 \%, 2 \%)$ but a decrease on crystallinity for low $\mathrm{Sr}$ ratio $(0.5 \%)$.This results have been matched with the results obtained from the XRD analysis for $\mathrm{Sr}-\mathrm{HA}$.

\section{Thermogravimertic analysis (TGA)}

The TGA plots illustrated in Fig.3 describe the weight loss along the investigated temperature range for the prepared samples. From this figure, it is observed that the mass loss during heating could be classified into two stages. The first stage weight loss occurs at 27 to $370^{\circ} \mathrm{C}$ due to the vaporization of physisorbed and chemisorbed water from the apatite lattice that's nearly about $7 \%^{(\mathbf{2 1 , 2 2})}$. Water monolayer, that is in contact with the HA surface (chemisorbed layer), was more strongly bound than the additional water layers (all physisorbed layers) that involved water/water contacts only. Chemisorbed water are found to be completely removed from the HA at about $300^{\circ} \mathrm{C}$, whereas physisorbed water are removed at about $20^{\circ} \mathrm{C}{ }^{(23)}$. The second stage weight loss occurs at $\sim 370$ to $1000^{\circ} \mathrm{C}$. The mass fraction lost in this temperature range was about $3 \mathrm{wt} \%$. As shown from the figure, temperature of phase transformation of HA $<\mathrm{S}_{1}<\mathrm{S}_{2}<\mathrm{S}_{3}$ which means that, Sr incorporation into HA increases its thermal stability.



Fig .3. TGA curves of control (HA) and Sr-HA samples as dried .

Bioactivity test (Activity of prepared samples in SBF)

Results of $\mathrm{pH}$ measurements for disc samples immersed for different periods in SBF solution are shown in Fig. 4. All discs of the different hydroxyapatites showed a decrease in the value of $\mathrm{pH}^{(23)}$. 


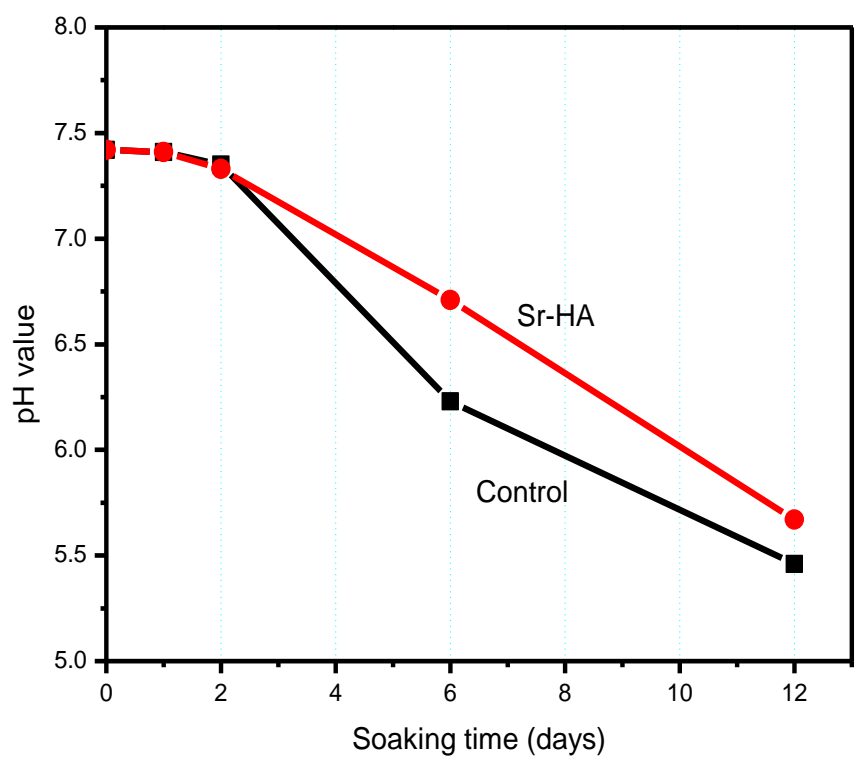

Fig. 4. Changes in SBF pH with time of immersion for control (HA) and $\mathrm{Sr}-\mathrm{HA}$ samples $\left(\mathrm{S}_{3}\right)$.

Figure 5.a and 5.b show calcium $\left(\mathrm{Ca}^{+2}\right)$, and phosphorus $\left(\mathrm{P}^{+5}\right)$ ion concentrations in the SBF solution after the different immersion periods, of synthesized apatite samples. As shown in those figures, $\mathrm{Ca}^{+2}$ and $\mathrm{P}^{+5}$ ions concentration decreased in the early stages for the prepared powders. This diminution is mainly due to uptake of these ions from SBF by the prepared samples to use them in the formation of carbonated (bone like) apatite layer on their surfaces. This decrement is followed by an enlargement in the ions concentration which means that the release of these ions from the samples into SBF solution is over than the uptake of calcium from SBF (degradation of samples overcomes the formation of the apatite layer) ${ }^{(13)}$.

Figure 5.c. shows $\mathrm{Sr}^{+2}$ ion concentration through the periods of immersion. As shown from the figure, there was an increase in the $\mathrm{Sr}$ ion concentration for the first period of immersion; this may be due to the release of $\mathrm{Sr}$ from the $\mathrm{Sr}-\mathrm{HA}$ samples in which the SBF solution does not contain any Sr content. Starting to increase is then followed by a decrease in the $\mathrm{Sr}$ ion concentration due to consumption of $\mathrm{Sr}$ ions from the SBF solution and their incorporation for the formation of an apatite layer. 


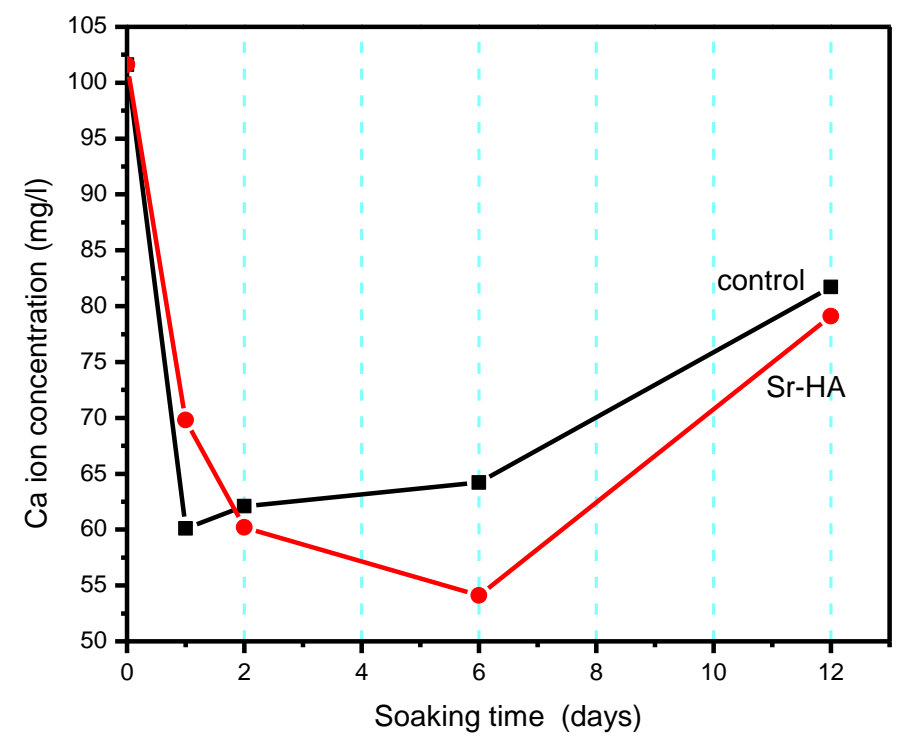

Fig. 5a. Calcium ion concentration in SBF of control (HA) and Sr-HA .

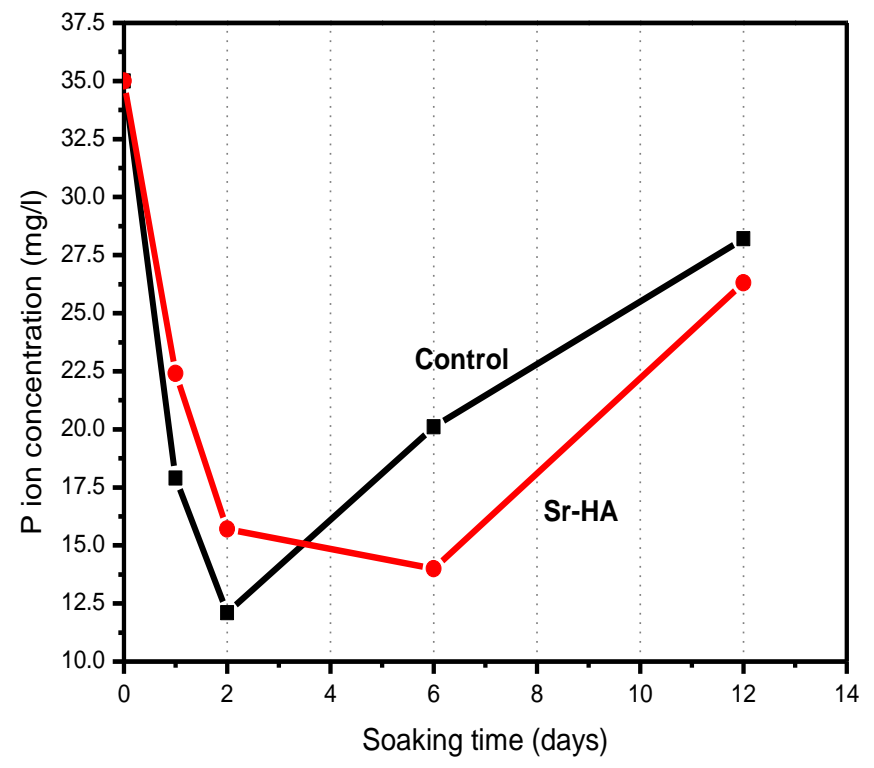

Fig. 5b. Phosphorus ion concentration in SBF of control (HA) and Sr-HA . 


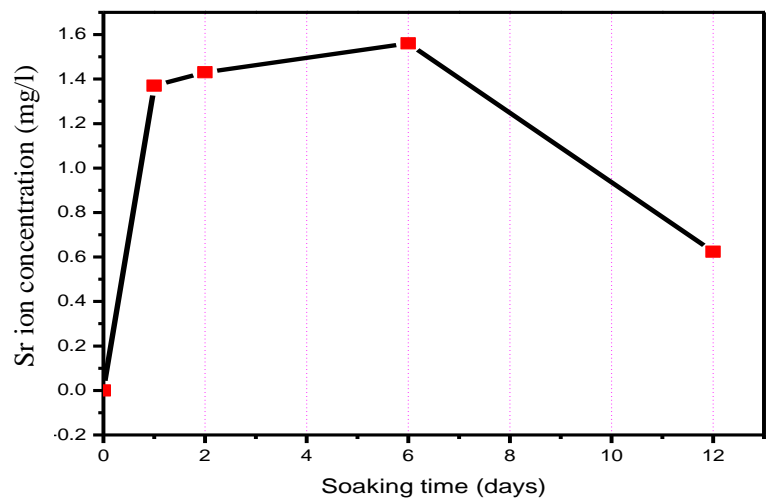

Fig 5.c. Strontium ion concentration in SBF of Sr-HA.

SEM of processed disc samples before and after the immersion in SBF for 1, 2 and 12 days are shown in Fig. 6 A new layer of nano-sized precipitates agglomerated in clusters is formed. They appear as bright tiny spots. As the soaking time was increased, the number and size of the agglomerated particles also increased. The increase of agglomerated particles is evident due to the formation of apatite or mineralization being taking place on the surface of the prepared Sr-HA samples.
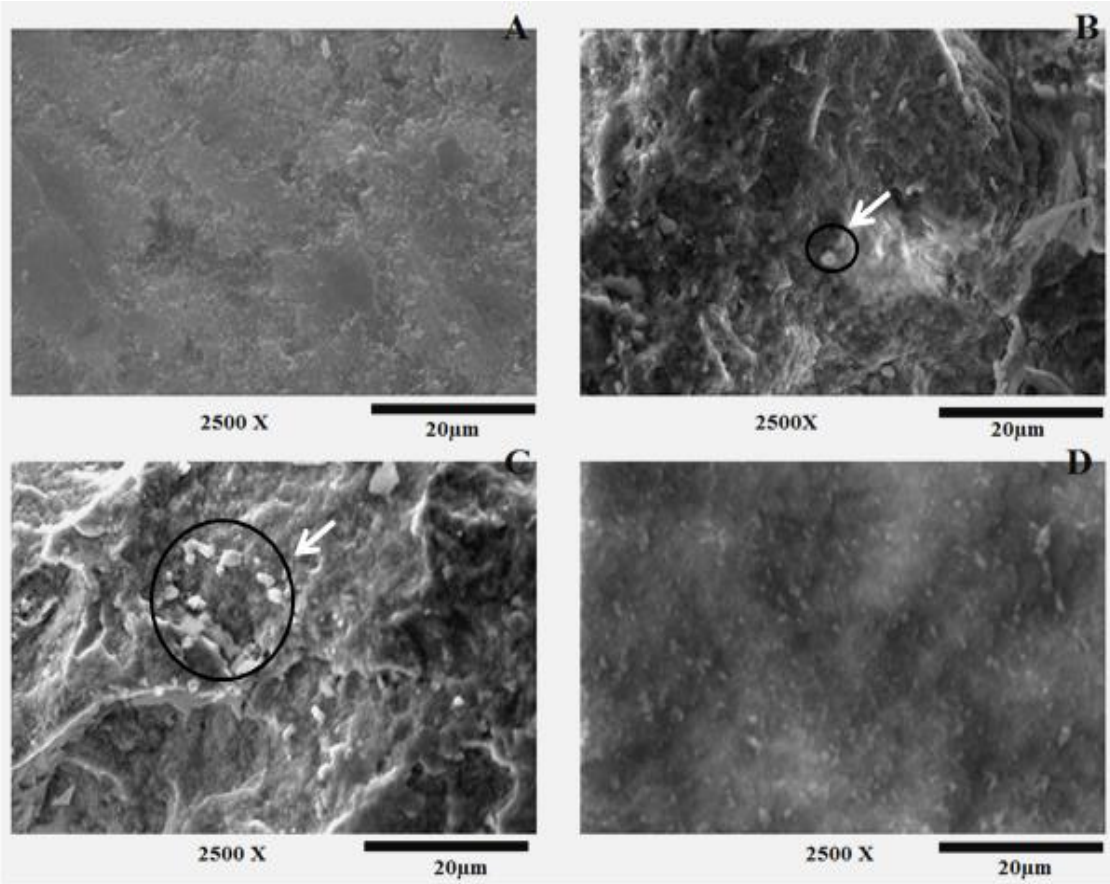

Fig.6. SEM of Sr-HA .A) Before immersion in SBF, B) After immersion for 1 day, C) After immersion for $\mathbf{2}$ day, D) after immersion for 12 day.

Egypt. J. Biophys. Biomed. Engng. Vol. 13 (2012) 


\section{Conclusion}

Sr-HA solid solutions with various $\mathrm{Sr}$ content were prepared by the coprecipitation method. Increasing strontium substitution for calcium in the HA structure provokes a linear variation in the cell parameters and in the infrared absorption bands, in agreement with the increasing mean dimensions of the cation. At variance, the effect of strontium on crystallinity and morphology changes with composition: Relatively low $\mathrm{Sr}$ replacement to calcium induces a decrease of the coherent length of the perfect crystalline domains and disturbs the shape of the crystals, whereas crystallinity, as well as mean dimensions of the crystals, increases at relatively high strontium contents. The incorporation of $\mathrm{Sr}$ into the lattice of HA evidently increases its thermal stability and bioactivity. Thus, this study shows that the development of strontium containing apatite represent a promising bone-grafting material for bone regeneration procedures.

\section{References}

1. Mabrouk, M., Mostafa, A.A., Oudadesse, H., Mahmoud, A.A. and El-Gohary, M.I., Effect of ciprofloxacin incorporation in PVA and PVA bioactive glass composite scaffolds, Ceramic International, $\mathbf{X}$, (2013).

2. Kolk, A., Handschel, J., Drescher, W., Rothamel, D., Kloss, F., Blessmann, M., Heiland, M., Wolff, K. and Smeets, R., Current trends and future perspectives of bone substitute materials from space holders to innovative biomaterials. Journal of Cranio-Maxillo-Facial Surgery ,40 ,706-718, (2012).

3. Murugan, R. and Ramakrishna, S., Nanostructured biomaterials, editor. Encyclopedia of nanoscience and nanotechnology, 7, 595-613 (2004).

4. Lowenstam, H. and Weiner, S., On "Biomineralization", Oxford University Press, Oxford (1989).

5. Nasab, M. and Hassan, M., Metallic Biomaterials of Knee and Hip - A Review, Trends Biomater. Artif. Organs, 24 (1), 69-82 (2010).

6. Tanejaa, K., Pareeka, A., Vermaa, P., Jaina, V., Ratana, Y. and Ashawat, M., Nanocomposite: An emerging tool for bone tissue transplantation and drug delivery. Indian Journal of Transplantation, 6 (3), 88-96 (2012).

7. Boanini, E., Gazzano, M. and Bigi, A., Ionic substitutions in calcium phosphates synthesized at low temperature. Acta Biomaterialia , 6 ,1882-1894 (2010).

8. Markovic, M., Fowler, B. and Tung, M. Preparation and comprehensive characterization of a calcium hydroxyapatite reference material . Journal of Research of the National Institute of Standards and Technology, 109 (6), 1-16 (2004). 
9. Sallam, S., Tohami, K., Sallam, A., Salem, L. and Mohamed, F., The influence of chromium ions on the growth of the calcium hydroxyapatite crystal. Journal of Biophysical Chemistry, 3(4), 283-286 (2012).

10. Klug, H. and Alexander, L.E., "X-ray Diffraction Procedures for Polycrystalline and Amorphous Materials ", Wiley-Interscience, New York (1974).

11. Aminian, A., Effect of silicon substitution on bioactivity of hydrothermal synthesized of hydroxyapatite nano-powders, M.Sc. Thesis, Amirkabir University of Technology, Tehran, Iran (2009).

12. Webster, T., Massa-Schlueter, E.A., Smith, J.L. and Slamovich, E.B., Osteoblast response to hydroxyapatite doped with divalent and trivalent cations. Biomaterials, 25, 2111-2121 (2004).

13. Kokubo, T. and Takadama, H., How useful is SBF in predicting in vivo bone bioactivity? . Biomaterials, 27, 2907-2915 (2006).

14. Bigi, A., Boanini, E., Capuccini, C. and Gazzano, M., Strontium-substituted hydroxyapatite nanocrystals . Inorganica Chimica Acta , 360 , 1009-1016 (2007).

15. Li, Z., Lam, W., Yangb, C., Xu, B., Ni, G., Abbah, S., Cheung, K., Luk, K. and Lu, W., Chemical composition, crystal size and lattice structural changes after incorporation of strontium into biomimetic apatite, Biomaterials, 28, 1452-1460 (2007)

16. Mobasherpour, I., Heshajin, M. S., Kazemzadeh, A. and Zakeri, M., Synthesis of nanocrystalline hydroxyapatite by using precipitation method. Journal of Alloys and Compounds, 430, 330-333 ( 2007).

17. Furuzono, T., Walsh, D., Sato, K., Sonoda, K. and Tanaka, J., Effect of reaction temperature on the morphology and size of hydroxyapatite nanoparticles in an emulsion system. Journal of Materials Science Letters, 20, 111-114 (2001).

18. Hanifi, A., Fathi, M. H. and Mir Mohammad Sadeghi, H., Effect of strontium ions substitution on gene delivery related properties of calcium phosphate nanoparticles, J. Mater. Sci.: Mater. Med. 21, 2601-2609 (2010).

19. Fowler, B.O., Infrared studies of apatites. I. Vibrational assignments for calcium, strontium, and barium hydroxyapatites utilizing isotopic substitution. Inorganic Chemistry, 13, 194-207 (2002).

20. Terra, J., Dourado, E. R., Eon, J. G., Ellis, D. E., Gonzalez, G. and Rossi, A.M., The structure of strontium-doped hydroxyapatite: An experimental and theoretical study, Physical Chemistry Chemical Physics, 11, 568-577 (2009).

21. El-Gohary, M.I., Tohamy, Kh. M., El-Okr, M.M. Ali, A.F. and Soliman, I., Influence of composition on the in-vitro bioactivity of bioglass prepared by a quick alkaline -mediated sol- gel method. Nature and Science, 11(3) , 26-33 (2013). 
22. O'Donnell, M., Fredholm, Y., de Rouffignac, A. and Hill, R. G., Structural analysis of a series of strontium-substituted apatites. Acta Biomaterialia, 4, 1455-1464 (2008).

23. Ibrahim, D., Mustafa, A. and Korowash, S., Chemical characterization of some substituted hydroxyapatites. Chemistry Central Journal, 5 (74),1-11 (2011).

(Received 25 /2 / 2014;

accepted 25/3/2014)

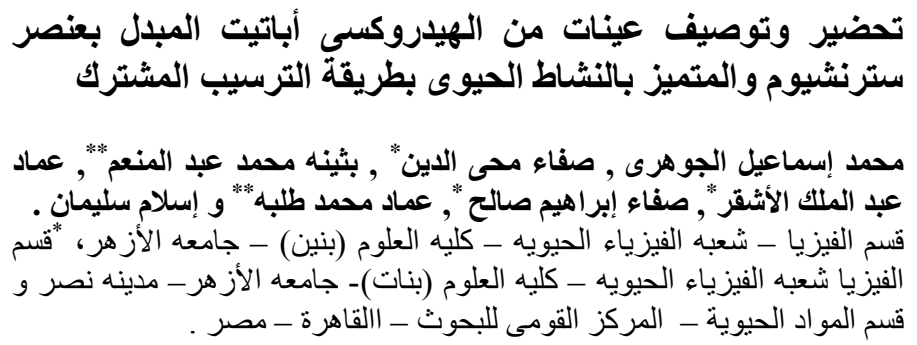

يعتبر عنصر الاسترنشيوم من أهم العناصر التى يمكن أن يبدل بها عنئ أنصر

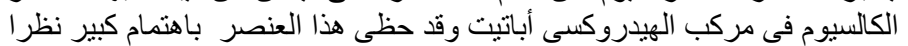

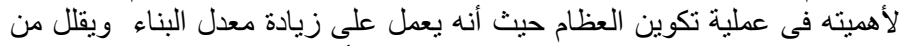

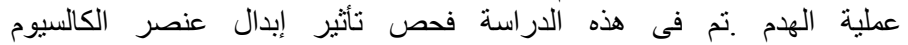



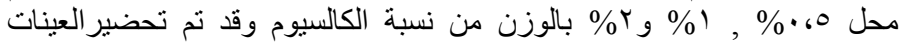

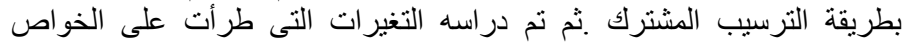

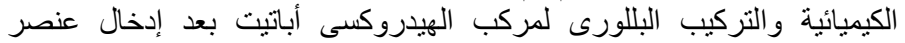



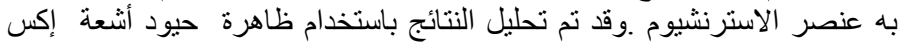

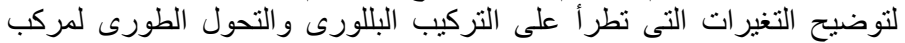

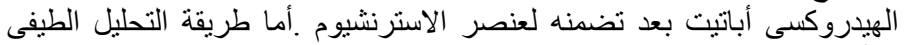

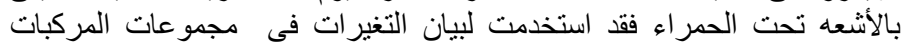

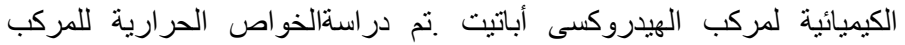

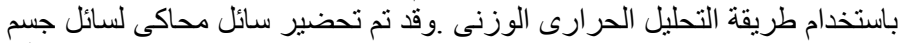

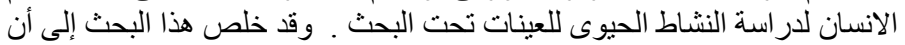

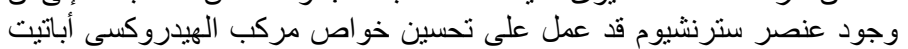
مما يتيح استخدامه فى إنتاج دعامات حيوية تستخدم فى التطبيقات الطبية. 